\title{
Towards Contestation of Perceptions, Distortions and Misrepresentations of Meanings, Functions and Performance Contexts in South African Indigenous Cultural Practices
}

\author{
Ndwamato George Mugovhani \\ Madimabe Geoff Mapaya
}

\begin{abstract}
Department of Performing Arts Department of Music, Tshwane University of Technology University of Venda
\end{abstract} Email: mugovhaning@tut.ac.za MapayaMG@univen.ac.za

\author{
Doi:10.5901/mjss.2014.v5n27p1201
}

\begin{abstract}
This article aims to contest the distortions and misrepresentations in the earlier writings of western scholars on the indigenous cultural practices of indigenous African language groups. The focus area will be Vhavenda communities around the Vhembe district of the Limpopo province of South Africa. This is the territory which was encroached by the various western missionary societies from as early as 1863. By 1940, most notable missionaries were almost well established in Venda. By the beginning of the 20th century, schools and hospitals also began to mushroom around Venda due to this missionary enterprise. Through interrogation of the various available sources; previous literature, our findings from participatory observations and the openended (sometimes-convergent) interviews and discussions, this article explores a number of the nomenclature and clichés that arose out of this missionary and ethnographic enterprise. The primary objective is to redress the resultant distortions of the information; with the objective of repositioning the distorted facts.
\end{abstract}

Keywords: Tshigombela, Malende, Tshikona, Malombo, indigenous African music, indigenous knowledge systems, Venda cultural practices.

\section{Introduction}

Contemporary studies have revealed a plethora of distortions and misrepresentations in the meanings, functions and performance contexts of some of the South African indigenous cultural practices. This is evident in research that was done primarily by western missionaries as well as the ethnographers that came with and after them mainly to conduct research on the history, cultures and traditions of the indigenous communities of South Africa. It occurred on a large scale around the late $19^{\text {th }}$ and early $20^{\text {th }}$ centuries.

This article will confine its discussion on the indigenous cultural practices of Vhavenda communities around the Vhembe district of the Limpopo province in South Africa. This is the territory 'which European missionaries encroached on a large scale from as early as 1863. The Dutch Reformed Church pioneered the move. The Berlin Lutheran Missionary Society followed them and established mission stations around Venda (now part of the Vhembe district) such as Beuster (later called Maungani) in 1872, Tshakhuma in 1874 and Georgenholtz (Ha Luvhimbi) in 1877. The third group was the Swiss missionaries in 1875, followed by the Presbyterian Church in 1902, then the Seventh Day Adventists in 1918 (Kirkaldy, 2000:3-4). By 1940, most notable missionaries were almost well established in Venda. By the beginning of the $20^{\text {th }}$ century, schools and hospitals also began to mushroom around Venda due to this missionary enterprise. Music patronage was mainly under the Christian churches during this period (Mugovhani, 2007).

This article aims to contest the distortions and misrepresentations on the indigenous cultural practices of indigenous African language groups of the Limpopo province in South Africa. It does so by interrogating a number of the nomenclature and clichés that arose out of the literature from this missionary and ethnographic enterprise. The primary objective is to redress the resultant perceptions and the stereotyped phrases or statements that were borne out of the ignorance that prevailed during this missionary and ethnographic enterprise, and to reposition the facts.

As stated earlier, the focus area will be Vhavenda communities around the Vhembe district of the Limpopo province. Perhaps it is prudent to declare that the article is not aimed at undermining the efforts of these earlier writers or negatively criticising them but to positively critic their writings in order to redress the resultant negative perceptions for the benefit of scholarship. 


\section{Methodology}

This paper emanates from a larger study that was commissioned by the South African government, particularly the Department of Arts and Culture during the period 2003-2008. The paper aims to contest some of the writings about the previously- marginalised cultural practices of indigenous African language groups of South Africa. It does so by interrogating a number of the nomenclature and clichés that are manifested in earlier scholarly writings from the missionary and ethnographic enterprise that prevailed amongst Vhavenda during the $19^{\text {th }}$ and $20^{\text {th }}$ centuries. It was during the numerous fieldworks and other sojourns whilst I was collecting and documenting data of the indigenous musical practices of Vhavenda that I prudently began to compare notes from the various available sources, previous literature, our findings from participatory observations and the open-ended (sometimes convergent) interviews and discussions, that I discovered a number of these misconceptions and distorted facts that have existed and were still perpetuated for decades. These are still available even in academically accredited sources, tragically, at the ignorance and oblivion of the people and cultural practitioners that these writings are supposed to represent, particularly village elders and their respective royal leaders who I have regarded as the primary/principal custodians of these traditional practices. In this paper, the views from the royal domain of the communities around which this research was conducted, namely, mešate/misanda/mitsindza, are included, together with contributions from elders and the practitioners. The paper confines its discussion within the indigenous cultural practices of Vhavenda communities of South Africa.

It is prudent to declare that the paper is not aimed at undermining the efforts of the earlier scholars or/and writers or negatively criticising them. This only serves to positively critic their writings in order to redress the resultant negative perceptions their writings have undoubtedly created about the so-called music of the "others". The primary objective is to redress the ignorance that prevailed during this missionary and ethnographic enterprise and the resultant perceptions and the stereotyped phrases or statements that were borne out of this, and to reposition the facts for the benefit of scholarship.

\section{Distorted and/or Misrepresented Views on Venda Musical Practices}

Vhavenda classify their musical practices according to age, gender, occasion, mood and customs. Some of such musical practices include Tshikona, Tshigombela, Tshifasi, Matangwa, Malende, and Malombo. In almost all Venda musical practices, dance, drumming, music (singing or instrumental playing), have been regarded as one, particularly in large ensembles such as those just mentioned.

Earlier scholars such as Kirby (1933: 354) and Blacking (1967: 21-23) classified these Venda musical practices as "dances" only; an assertion that warrants contestation. Tshikona, for example, is one of the oldest indigenous Venda traditional pipe-blowing, drumming and dance musical practices. It is therefore significant to correct the perception that such a very popular and unique cultural practice that comprises instrument-playing (blowing of nanga), dancing and drumming could be collectively termed a "dance". It is inconceivable that such a misrepresentation or distortion could be arrived at, and that such misrepresentations or distortions which are misleading the broader academic readership have been perpetuated down the years. Even quite recently, another display of ignorance is still manifested in Nemapate's writings. Nemapate (2010) captures Tshikona as a royal "dance" traditionally for males. The latter writer even goes further to sow confusion by interchangeably using "dance" and "band" to describe this royal cultural practice (Nemapate, 2010).

The other Venda cultural (musical) practice worth interrogation is Malende. This is performed at davha (communal work-parties) and murula (guest parties). Malende comprises call-and-response singing, drumming, dancing and handclapping. The soloist is usually the leading singer (caller) and dancer, whilst the majority of the musicians offer a response by singing and clapping, with a few on the drums (Mugovhani, 2007:184). Blacking correctly describes Malende as "songs that lighten the labour of communal work-parties" (Blacking, 1964:23). However, statements such as "The success of a session of beer songs depends on both the beer and the presence of at least one good song-leader" (sic nambi) and the careless conclusion that "Beer-songs are sung at any time of year when there is beer to drink" (Ibid: 23-24 and 332) should be challenged. In other words, Blacking's postulation is that the performances of malende depend on the availability of beer! This very disturbing misrepresentation can also be found is a much earlier study by Stayt (1931) who described Malende as an informal "dance" which begins towards the end of a beer drink. This paper contends that beer drinking cannot be generalised. There are predominantly well-organised occasions where Malende is performed not because of beer drinking. Malende performances have played an important part in family life amongst Vhavenda; at occasions such as during discussions about marriage arrangements, when Vhavenda celebrate the birth of a child or a celebration after a girl or a boy has graduated from an initiation school, which "generally give rise to singing and dancing" (Blacking, 1964:22), but that does not make one to carelessly conclude that such performances should be termed "beer 
songs." Another very controversial statement appears on page 23 of Blacking's Venda Childrens' Songs, which reads; "Beer songs for solo performance on an instrument." This sows confusion. The impression this statement might quite readily create is that indeed indigenous musical instruments could be played even by drunken individuals. Such misleading impressions are hereby challenged, for these borders on denigration or derogation of other people's esoteric musical practices.

Following on after Stayt and Blacking's writings, the words "beer songs" feature extensively in Kruger's doctoral thesis (1993). He wrote;"'Family festivities accompanying a birth, wedding or graduation usually involve eating, drinking and the performance of beer songs" (Kruger, 1993: 14-15). Kruger goes on to state that "Venda traditional beer songs are known as Malende." In other words Kruger correctly recognises that these traditional songs are actually called Malende. The rich educational, cultural and musicological properties of this practice (Malende) should not have been lost in its unfortunate association with beer, as in "beer song". Perhaps to his credit, Kruger is able to discern that the musical practices are important for strengthening bonds of friendship and neighbourliness; and that the performance requires good cooperation between musicians. Had he not encountered Blacking's writings, he would perhaps have invested much effort in learning about other properties that are embedded in practices such as Malende. Because of this unresolved paradox, he leaves readers wondering how "good cooperation" amongst the performers can be maintained under the influence of alcohol (beer) if he calls these "beer songs".

In Venda tradition, several occasions warrant the performance of Malende. Usually, this is when Vhavenda are proud of family or communal accomplishments. For instance, the communal work party called davha occurs when an owner of a piece of land requests members of the immediate community to help in the fields (either hoeing or weeding). Usually after the communal work has been completed, the work-party is provided with refreshments at the home of the sponsor. This is usually in the form of food (porridge and meat) and beer. The music and dance that is performed at davha is called Malende. In another example, families who are related by marriage send each other gifts, which may include beer', which is called murula. Malende is performed in such occasions, not because of murula, but due to the joyous celebration of the occasions. Furthermore, in Venda culture and tradition, musical practices even serve to maintain ties between different communities. This musical expedition is called bepha. Unfortunately, due to the misconception that developed out of the observations of the earlier non-Venda researchers, these scholars dismissed the importance of the role of music and dance practices by framing them as "beer songs". That traditional beer-drinking occurs during these cultural performances does not reduce their significance to mere "beer songs". Surely, many societies in the world have different ways of celebrating, and some of the provisions in such occasions may include food, music, dance and indulgence in some form of alcoholic beverages. Why are such occasions not termed "beer song" occasions?

There is an explanation for these mishaps. In the then Venda homeland during 1863 to about 1969, the church as the main institution denigrated indigenous Venda music as 'pagan' and 'anti-Christian'. Music patronage was mainly under the Christian churches during this period. There was generally a negative attitude among non-Venda researchers or scholars towards indigenous art, and the indigenous music of indigenous Vhavenda was not considered to merit serious scientific study (Blacking, 1965). Hence one of the earlier scholars (1964:23) carelessly concludes and writes, "Beer-songs are sung at any time of year when there is beer to drink".

This is further evidence of the confusion that arises out of scholars who misconceptualise nomenclatures and clichés to cultural practices of "the others". Perhaps another pertinent question one could ask would be whether it was not possible for these earlier writers to rather use the indigenous original nomenclature for these musical practices instead of unsuccessfully attempting to find western concepts for them. It would have been very considerate for the non-Vendaspeaking scholars to use the Venda nomenclature that the informants provided them with instead of them trying to design their own western conceptualised and fabricated ones. What was wrong with mentioning Malende as Malende -instead of coining the musical genre "beer songs"? Surely, the derogatory nomenclature (beer songs) cannot obtain precedence over the indigenous original and authentic one (Malende).

\section{Further Deficiencies in Scholarship}

Kirby (1933: 354) classifies Tshigombela-another Venda musical practice-as "dance" only; an assertion that also warrants correction. As state earlier, it is significant to state that in almost all Venda musical practices, music and dance have been regarded as one, particularly in large ensembles such as Tshigombela. Mapaya (2013) refers to a similar tradition amongst Bahananwa of Limpopo in South Africa as a song-dance compound. It is therefore incorrect to refer to this musical practice as "only a dance". Meanwhile, whereas Blacking (1967: 21-23) correctly recognises Tshigombela as a "song and dance performance done by unmarried Venda girls", calling it an "amusement" song and dance performance is a misrepresentation of musical and epistemological facts. Tshigombela was conceptualized for and performed in a 
number of objectives and functions. Indeed it served to entertain guests at the royal court or create a serene ambiance that signifies the prestige of the environment. The splendour of Tshigombela serves to enhance the image of the ruler as the patron and sole custodian of the tradition (Makhuvha Royal Family, 2008). Secondly, it may form the "sound track" of a royal musical expedition. A ruler could organize Tshigombela musical expeditions to the other rulers under him around his/her territory. (Vho Mmboneni Matamela Sarah Tshivhase, 2008). Tshigombela music and dance ensembles therefore serve to maintain ties between different communities. Parties of musicians would sometimes be sent by one ruler to another's territory to entertain and to be entertained for a few days. Kruger (2002) rightfully notes that Tshigombela fulfils an ambassadorial function and strengthen the solidarity of ruling families. As previously stated, this musical expedition is called bepha.

Bepha could be sent by one ruler to another for a variety of other reasons. The most common of sending out these expeditions is to express sympathy ( $u$ imela) for the death of a member of the ruler's lineage. In some instances, an expedition could be sent out to a commoner who has trespassed. And the commoner would be obliged to slaughter a beast in order to feed the performers and also to produce musumo (reparation, usually in the form of parts of the slaughtered beast [cow]) to give back to the ruler as a form of an apology (Vho Mmboneni Matamela Sarah Tshivhase, 2008).

Thirdly, Tshigombela may be used to keep the girl-children away from mischief. Normally, the performers were adolescent girls, and this cultural practice assisted in introducing them gradually to patterns of maturity, responsibility and political authority. Resultantly, bonds of friendship also develop between girls, their mothers and other female involved in organizing such performances (Kruger, 2002).

Meanwhile Blacking (1967:21-2) misleadingly describes Tshigombela as a "traditional amusement dance and song for unmarried girls". The functions mentioned above aptly illustrate that this cultural practice has always been multifunctional, and 'amusement' was just one of the minor objectives, if not an incidental occurrence. Tshigombela was not just for mere "amusement".

\subsection{Nomenclature that degrades indigenous episteme and institutions}

Apart from the aforementioned flaws, many nomenclatures that depict the attitude of early scholars towards African existence abound. I will refer only to two examples: one about an instrument and the other about how African royal leadership was perceived by earlier scholars.

This study also explored one of the instruments that were popularized in South Africa by Vhavenda; Mbila. It is significant to state that Mbila music may not be classified as one of the original indigenous Venda instrument. However, it is important to note that there exist three different types of instruments that produce Mbila music, and these are Mbila dza madeza, Mbila tshipai and Mbila mutondo. Each key on its own is called mbila. For fear of digressing from the focus of the paper, I may not elaborate on the differences of these instruments, except to state that mbila dza madeza have double tone rows, whilst mbila tshipai has one tone row. And mbila mutondo which is made up of flat carved wooden keys and has many rows is the largest (the precursor to the contemporary marimba). The keys of Mbila dza madeza and Mbila tshipai are played only with the thumbs.

Some earlier writers recorded it and termed this esoteric instrument "kaffir piano" in their literature. The term "kaffir piano" warrants contestation, for it is derogatory, condescending, and at worst, displays the intolerable form of ignorance. The term is associated with the colonial and apartheid South Africa. It was almost invariably used by the Dutch colonisers and later the Afrikaners during the Apartheid era to classify African people in South Africa. This term has thus acquired a distinctly derogatory meaning in the context of South African history. It is racially regarded as being highly offensive in the same way as "nigger" in the United States and other English-speaking countries. Again, it would have been prudent for these earlier writers to rather use the indigenous original nomenclature (Mbila) instead of unsuccessfully attempting to find a western concept for it, not unless it was deliberate and opportune on their part to want to use the concept "kaffir" for motives best known to them. At least those who lately termed it "thumb piano" due to "the fact that it is played only with the thumbs" (Akpabot, 1976:42) were reasonably considerably respectful or considerate.

The question that this study begs to ask is: With this type of literature still in our bookshelves, where are we heading to? Qua Vadis? Must we leave the past as it is; move on without the necessary redress? Or attempt to rewrite the past information and correct the negative perceptions the earlier writings have undoubtedly created?

Another terminology that serves to degrade African societies permeates earlier literature on African royal leadership and their cultural royal settings. Perhaps some might be beginning to wonder what the royal leadership and cultural settings have to do with this paper. A quick response would be; it is within theses settings or environments that most of the study under scrutiny occurred. Therefore in order to conclude this argument appropriately, the cultural milieu 
in which the musical performance takes place should be included in order to understand the study in its totality.

Amongst Vhavenda societies, the social hierarchy between royalty and commoners invariably comprises (from top to bottom) Thovhele, which denotes the highest authority in the land (Vendaland), then Khosi (a King) who rules over one of the territories in the land (there were several territories with their respective kings (mahosi) in Vendaland), thereafter Vhamusanda who administers a particular village (there are several villages, each with its own Vhamusanda), then it cascades to Gota and Vhakoma and finally the families of the commoners. Such terms are scarcely used by scholars of western orientation in their writings. Instead, the highest reference to the highest authorities amongst Vhavenda in their vocabulary is a "chief". Whereas nations such as British, Swedes, Danes, just to mention a few, can have rulers recognised as "kings", Vhavenda and many other African nations were not worthy to have kings in the eyes of the western scholars. Instead, the highest level or honour any of the rulers could be elevated to would at most be a "chief".

Moreover the royal dwellings of the ruler is referred to as a "chief's kraal", not the fitting and authentic representation of the royal dwellings such as Musanda (Tshivenda), Mosate (Sotho) or Ntsindza (Xitsonga). Meanwhile, the term "kraal" generally refers to an enclosure for keeping a herd of cattle at the end of a day. Kraal is an Afrikaans and Dutch word (also used in South African English) for an enclosure for cattle or other livestock located within an African settlement or village, surrounded by a palisade, mud wall, or other fencing, roughly circular in form. Although during the period of colonisation European South Africans and historians commonly referred to the type of dispersed homestead characteristic of the Nguni-speaking peoples of southern Africa as a kraal, modern ethnographers have long recognised that its proper referent is the animal pen area within a homestead. Folds for animals and enclosures made especially for defensive purposes are also called kraals. How the earlier western writers came to equate an African ruler's royal courtyard with a kraal is beyond human reason and inexplicably disturbing. Whether the omission to recognise the existence of such a status amongst Africans was deliberate should be to left to anyone's imagination. It nonetheless suffices to posit that this necessitates the long-overdue redress.

Unless a paradigm shift is established, performing arts students, particularly Africans, and contemporary scholars will continuously be haunted by earlier scholarly writings that perpetuate concepts that represent a paradigm bent on denigrating other cultures. The need for specific modes of enquiry in the indigenous cultural practices of previously marginalised societies beckons in South Africa.

\section{Conclusion}

Authentic history and culture of a number of previously marginalised African societies of South Africa is rather very sketchy and dominated by distortions and misrepresentations. In order to redress these misconceptions, distortions and misrepresentations highlighted herein, it was incumbent for me to embark on an oral tradition-sensed approach; a methodology that engages the custodians about their history and culture. I contend that the search for this history and culture could not be complete without considering the centrality of oral history. This study has benefitted from the fact that the research was conducted by people who are not merely academics, but African academics who belong to the communities under scrutiny. I believe it is possible for non-scholars to adapt to the mode of enquiry that would begin to sift sentiments from facts. Such clichés and nomenclatures as have been highlighted in the study should be done away with if the national imperative of redressing the past imbalances and levelling the playing fields is to be realised.

The study hereby recommends and advocates for the application of the original indigenous nomenclature that were conceptualized by the custodians of the language and the cultural practices. This would help redress, restore, reaffirm and reposition the history, language, meanings, functions and performance contexts of the cultural practices and traditions of indigenous South African societies.

\section{Acknowledgements}

For the study yielding this article I will forever be indebted to the South African Government's Department of Arts and Culture for affording us the privilege, through their funding, to lead a research project team that conducted research on the indigenous cultural practices of the people of Limpopo. The project was funded during the years 2003-2008.

\section{References}

Akpabot, S.E. 1976. Fugitive notes on Notation and terminology in African Music, in The Black Perspective in Music, Vol. 4 , No. 1. Foundations for Research in the Afro- American Creative Arts Publishers

Blacking, J. 1964. The Cultural Foundations of the Music of the Venda, with Special Reference to the Children's Songs. University of the 
Witwatersrand, Unpublished Ph.D. thesis.

Blacking, J. 1967 Venda Children's Songs. Johannesburg: Witwatersrand University Press.

Kirby, P.R. 1933. The Reed-Flute ensembles of South Africa: A study in South African Native Music. In Journal of the Royal Anthropological Institute of Great Britain and Ireland, vol.63. London: Royal Anthropological Institute of Great Britain

Kirkaldy, A. 2000. Capturing the Soul. Encounters between Berlin Missionaries and Tshivenda-speakers in the late 19th Century Vendaland. PhD Thesis, Cape Town: University of Cape Town.

Kruger, J.H. 1993. A Cultural analysis of Venda songs. Unpublished PhD Thesis, Rhodes University, Grahamstown.

Kruger, J.H. 1998. Three Tshivenda Beer Songs with Guitar Accompaniment. The Talking Drum Newsletter, Rhodes University, Grahamstown.

Kruger, J.H. 2002. Contemporary changing socio-economic patterns in Venda cultural practices. Paper presented during the Travelling Institute Research Seminar. Thohoyandou, University of Venda.

Mapaya, M.G., 2013. Investigating Mmino wa Setšo (Indigenous African Music) as Practiced by Bahananwa in Limpopo Province, South Africa: Towards Ordinary African Musicology. PhD Thesis. Thohoyandou: University of Venda.

Mathase, 2013. Interview with Mugovhani NG on 20 January 2013. Thohoyandou.

Mugovhani, N.G. 2008. "Tshikona: Meaning, Function and Performing Context in Society; with specific reference to Vhavenda in South Africa.", A paper presented at the CHOTRO International Conference at the Indira Gandhi National Centre for the Arts in New Delhi, INDIA, 01-06 January 2008.

Mugovhani, N.G. 2009. "Mbilamutondo music and instruments in Venda culture", published by the South African Journal of Art History Vol. 24, Number 3, 2009.

Nemapate, M.A. 2010. A Study of Structure, Meaning and Performance in Tshivenda Traditional Songs. Unpublished Masters Dissertation, Mankweng, University of Limpopo.

Stayt, H.A. 1931. The Bavenda. Cape Town: Oxford University Press.

Tshivhase, V.M.S. 2008. Interview with Mugovhani NG on 06 September 2008. Thohoyandou.

Worsley, P., 1997. Knowledges: What Different Peoples Make of the World. London: Profile Books. 